\title{
Approaches for the planning and implementation of Industry 4.0
}

\author{
Barz Cristian $^{1}$, Jalba Claudius Klaus ${ }^{1}$, Erdei Zoltan ${ }^{1}$, Hahn Sarah Myriam Lydia ${ }^{2}$ \\ ${ }^{1}$ Faculty of Engineering, Technical University of Cluj Napoca, North University Center of Baia Mare \\ ${ }^{2}$ Faculty of Automation and Computer Science, Technical University of Cluj Napoca
}

\section{Article Info}

Received Dec 1, 2018

\section{Keyword:}

Automation

Networking

Industry 4.0

Technical revolution

\begin{abstract}
The continuous degree of automation in industry and the networking of individual components such as machines, robots, autonomous drive systems, control units etc. opens new possibilities for linking production and service or, integrating customers and business partners into value-added processes. In this technical revolution, machines should be able to decide independently and even contribute to developments. Before the implementation, planning should be carried out in the planning stage, where Industry 4.0 can be implemented, what should be achieved, how can corresponding plans be implemented, and what aspects of security, machine ethics, information ethics or work ethics must be considered. While answering these questions, it can be found out what resources of material and immaterial nature are needed and what are the advantages and disadvantages that should be expected.
\end{abstract}

\section{Corresponding Author:}

Barz Cristian,

Department of Electrical Engineering, Electronic and Computers,

Technical University of Cluj Napoca, North University Center of Baia Mare,

Dr. Victor Babes Street 62A, Baia Mare 430083, Romania.

Email: cristian.barz@cunbm.utcluj.ro

\section{Introduction}

Industry 4.0 is a term that was first presented at the Hanover Fair 2011, by Henning Kagermann (acatech), Wolf-Dieter Lukas (Federal Ministry of Education and Research) and Wolfgang Wahlster (German Research Center for Artificial Intelligence - DFKI GmbH). Subsequently, an Industry 4.0 working group was formed under the chairmanship of Siegfried Dais (Robert Bosch $\mathrm{GmbH}$ ) and Henning Kagermann, who developed recommendations for this future project and will continue to be supported by the German Federal Government [3], [6].

The term Industry 4.0 is intended to suggest that a fourth industrial revolution is taking place where production is networked with communication systems so that it can organize itself. In this value-added chain, people and machines are to (will be able to) communicate and cooperate directly with each other, from product development to logistics and after-sale management [5], [10], [11],

The concept of Industry 4.0 consists of the following design options [4]:

- networking of machines, devices, sensors and people so that they can communicate via the IoT;

- sensor data expands system information of digital factory models to create a virtual image of the real world;

- assistance systems support humans with the help of visualized and understandable information. This allows decisions to be made and problems to be solved more quickly. In addition, people are physically supported in strenuous, unpleasant or dangerous work;

- decentralized systems can make independent decisions to perform tasks as autonomously as possible. Only in exceptional cases, for example in case of disruptions or conflicting goals, they transfer the tasks to a higher authority. 
This article will continue to outline some of the opportunities and objectives of Industry 4.0, with some examples, so that the reader will not only know the technical preconditions of this industrial revolution but will also be confronted with the social and moral aspects that this technology development entails.

\section{Industry 4.0}

After the severe economic crisis of 2007/2008, most European countries have cut back their industrial production or relocated abroad. Only a few Eastern European countries such as Poland, Hungary or Romania were able to increase their production. In contrast to Great Britain and France as large industrial nations, Germany was the only Western European country to increase their industrial production (Figure 1) [8].

For the most part, Germany owes this stroke of luck to a well-organized and well-functioning infrastructure with a very strong and innovative industry. However, the volatile markets and non-European competition have shown that the industry needs to adjust very quickly and flexibly to its customers if it wants to continue its growth course.

In a study under the direction of the Fraunhofer Institute, where well-known experts and 661 companies were involved, the following goal was formulated: "to recognize the possibilities of the new technology and above all to seize the opportunity to actively shape the future of our production" [8], [9].

From this point of view, Industry 4.0 can be understood as a push into a new industrial future, where value creation processes should be made smarter and more efficient.

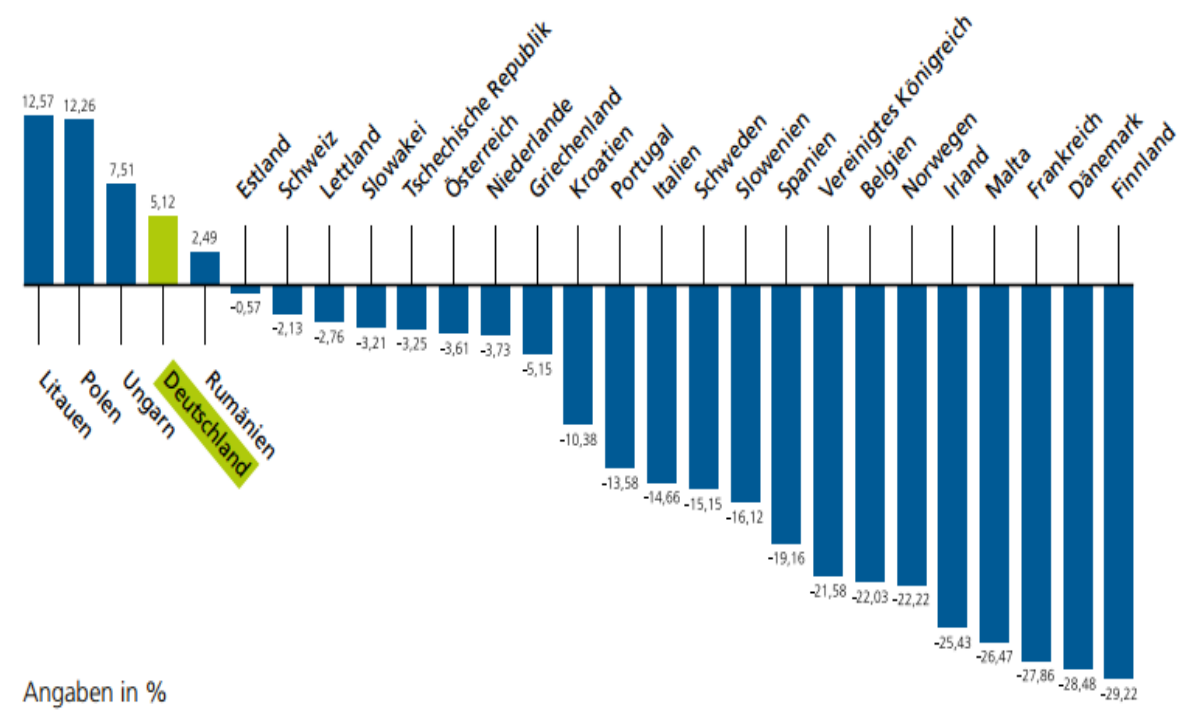

Figure 1. Development of the industrial production in Europe after 2007

To achieve this goal, companies are facing major challenges. For example, you need to link IT technologies with production technologies to create innovative products or services. In addition, technical standards must be developed to enable communication between man and machine or between machine and machine. Because wages in the Western auto industry have risen sharply in recent decades, it is increasingly lucrative for industry to fully automate production processes. This automation is strongly enforced using sensors and industrial robots (Figure 2) as shown by BMW US Manufacturing Company (2013) [2].

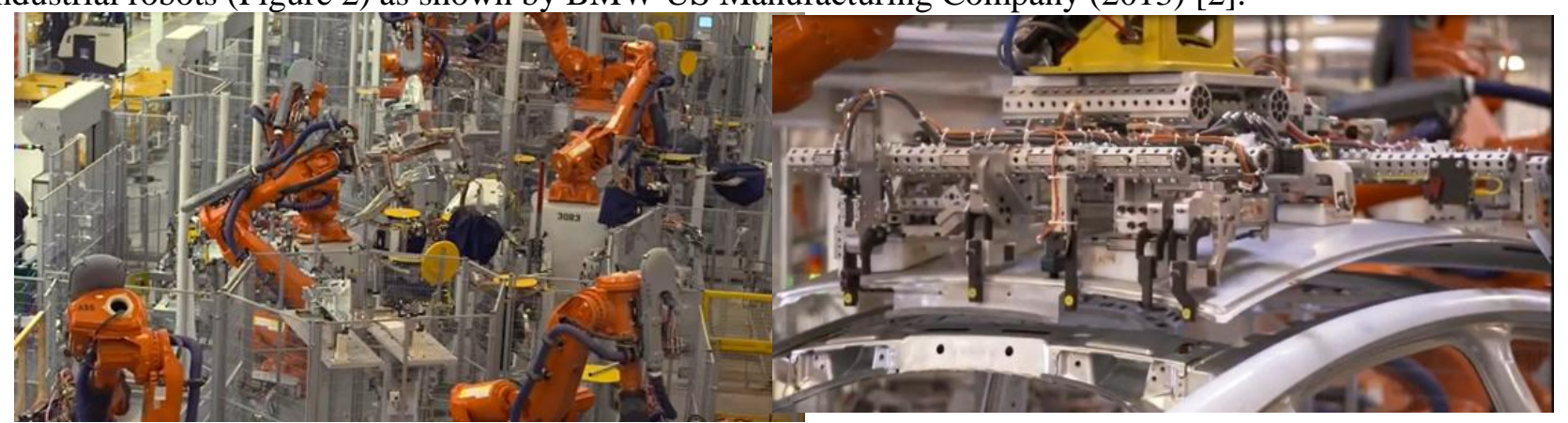

Figure 2. Assembly line with robots 
In this way, robots and machines can handle very strenuous and hazardous work, but this leads to a loss of countless jobs [2]. By using robots, according to a study by the McKinsey Global Institute, a share of 24 percent will be eliminated by automation, especially in Germany, by 2030, almost a quarter of the working hours. By then, this development should be felt in the USA at 23 percent, in China at 16 percent and in India at 9 percent.

Germany is particularly affected by the structural change, because the higher wages in Germany provide a greater incentive to replace manpower with machines. Up to twelve million employees, or up to a third of all workers, would have to acquire new skills or look for a job in another industry. Activities such as clerks are primarily affected, but also locksmiths or cooks. However, the workforce is expected to fall by three million by 2030 due to demographic change [8].

In the meantime, Industry 4.0 has become more of a synonym for the term smart factory, while changes in value creation structures are largely ignored. In fact, huge steps have been taken in fully automated industrial manufacturing where it is possible to integrate the value chain from product development to logistics and customer involvement in the further development of new products. But Industry 4.0 is also intended to cover other areas of economic life.

An important area where very high growth rates are achieved is the acquisition of information of all kinds. The flood of data is becoming so important that the data is referred to as the "new raw material" [7].

In this context, the legal foundations for data security and data ownership must also be created. The image symbolically shows data generators such as surveillance cameras, automobiles and aircraft with integrated navigation systems, Internet usage, or solutions for intelligent house management systems (Figure 3) [12].

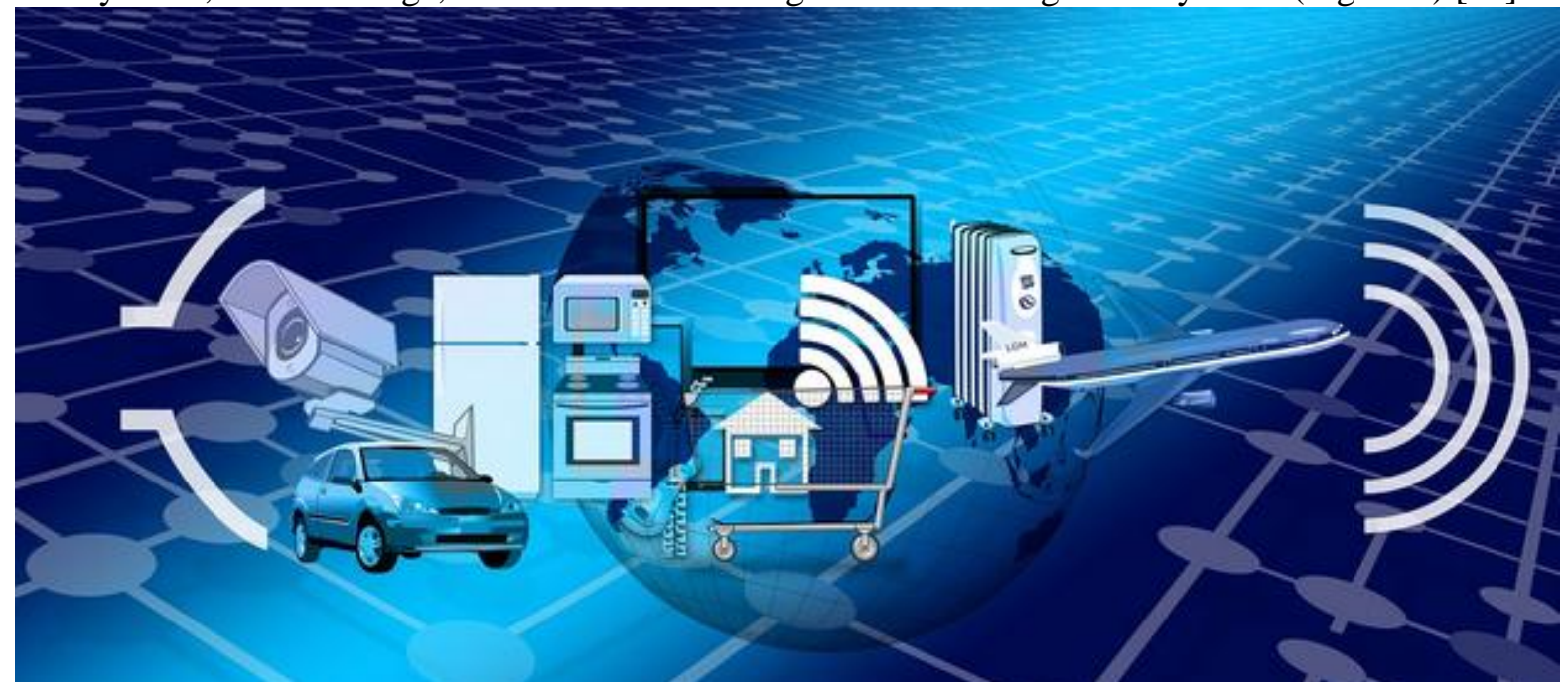

Figure 3. Data providers

More and more companies want to participate in this huge flood of data. By collecting, analyzing and evaluating this wealth of information, many business fields can be deepened, and new ones developed. The data has already become a profitable economic factor without the potential data providers being asked or even informed.

An example is the amount of data that is provided by moving vehicles, where automakers collect and evaluate data for internal purposes, or provide insurances. Data from moving vehicles, for example, can be used via Google Maps for the generation of motion profiles. Google can use smart phones or tablets owners in the moving vehicles on Android devices to determine the current traffic situation in real time. This allows Google to create and commercialize another information service without the consent of the unsuspecting data providers [12]. Watson Discovery is designed to simplify data entry with simple tools. You can edit your own data as well as publicly available data, or you can use data crawler and conversion API (application programming interface, Figure 4) calls to convert and prepare data for your own purposes [13], [14]. 


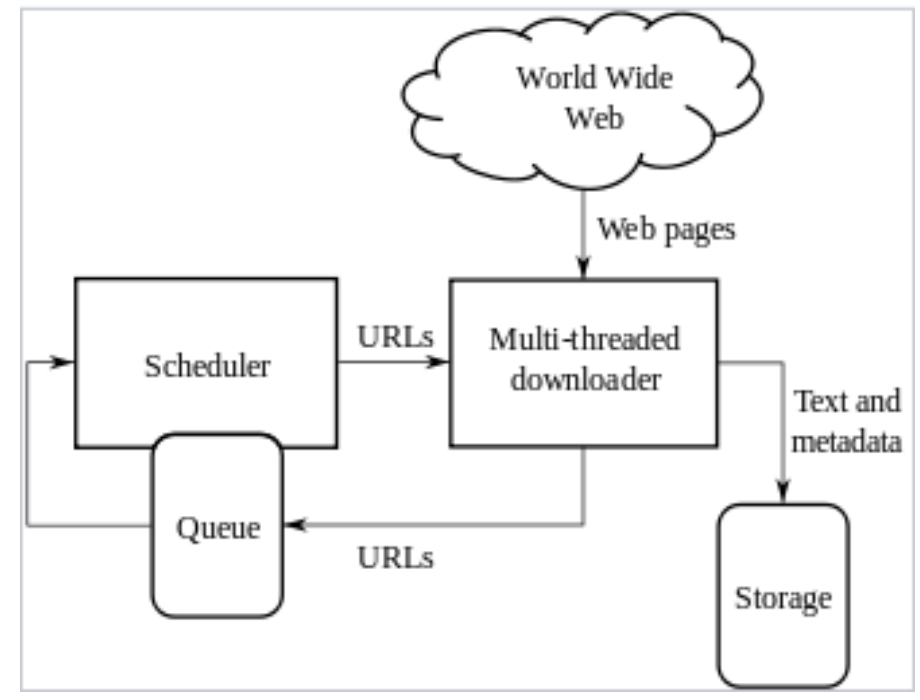

Figure 4. Application programming interface

This platform also allows the processing of natural language, mood or sound. This can improve the quality of the data before it is processed. These tools make it easier to develop new systems and improve collaboration in teams.

The current legal system recognizes ownership of property or intellectual property, but not ownership of data generated, for example, by a smart home: room temperatures, food supplies in the refrigerators, presence of people in rooms, favorite programs, supplier selection, etc. Thereby inevitably raises the question of who owns this data, which can be exploited via the Internet of Things? Is it permissible for anyone to access it? These are legal questions that are unclear.

\section{Artificial Intelligence}

In addition, the subject of Industry 4.0 must be understood by the professional world and generally accepted by society at large. Think of autonomous driving systems. When robots are used in logistics to transport goods faster and more efficiently in a warehouse without hurting people, this is a remarkable invention (Figure 5).

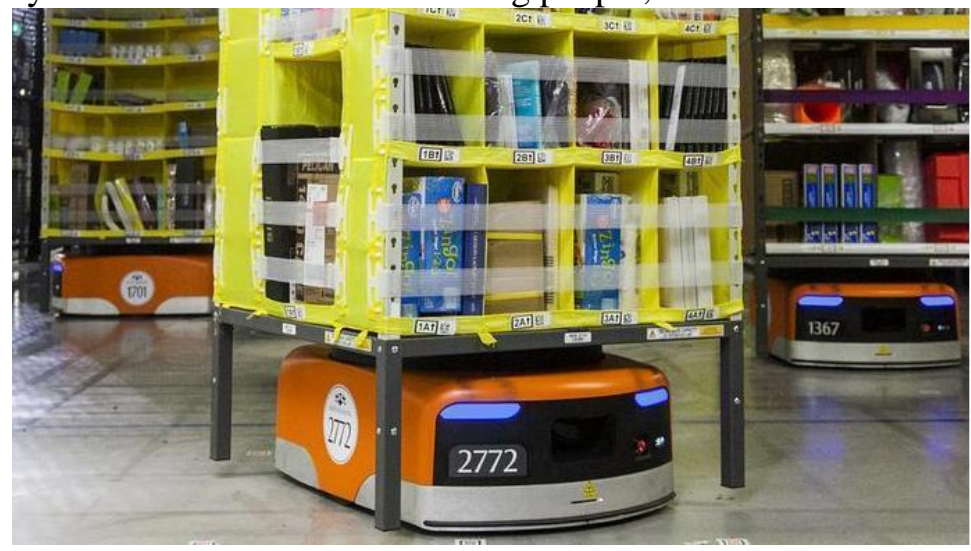

Figure 5. Logistic robots used by AMAZON [15]

However, it takes some time to get used to the idea of a transport system being used to transport people completely automatically, at high speed, without the need of a driver. The driverless Dubai Metro should be taken as an example. Because the metro runs on rails and no obstacles are to be expected on the line, passengers can get used to this system very quickly. In addition, the trains of this kind of transport system run very punctually and efficiently. At first glance, the use of automation in conjunction with a kind of artificial intelligence only brings benefits that should serve people.

Similarly, it is with flights with an autopilot (Figure 6). When passengers sit in the cabin and do not see how the plane is navigated, they feel relatively safe. Technically, a flight with the autopilot is relatively safe and unproblematic with today's possibilities. However, to give passengers an extra sense of security, pilots 
continue to be deployed, not least because they want to detect and assess potential dangers better than computer systems.

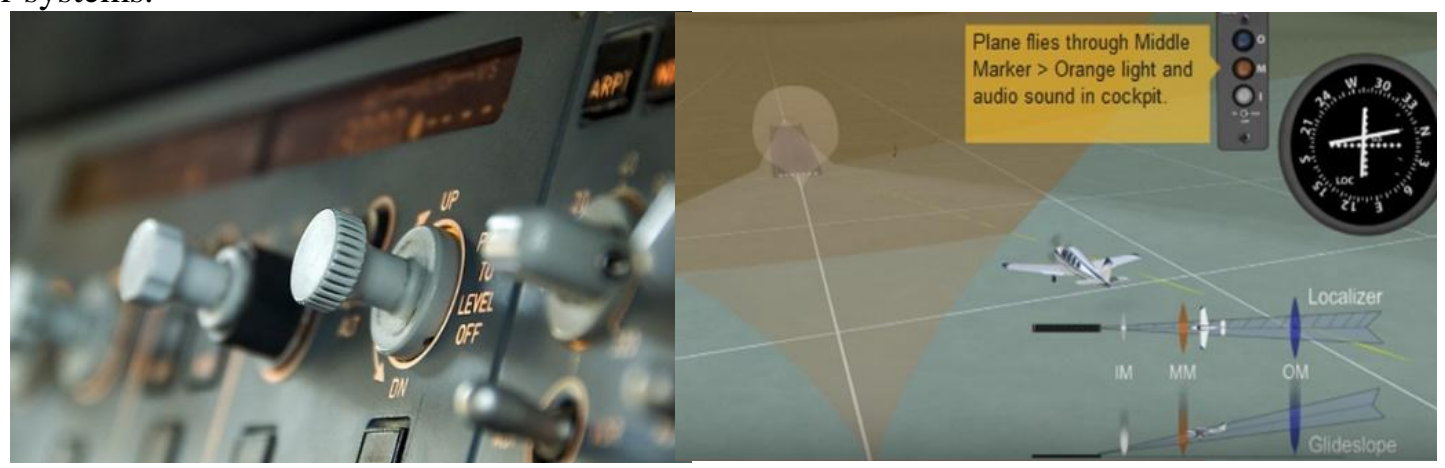

Figure 6. The autopilot control panel in an Airbus A320 and navigation with it [16]

However, it is different when a driverless transport system is used in normal road traffic. The inhibition threshold is the greater with how more confusing the traffic situation is. Many threats of various kinds lurk in this environment, which are difficult for programmers to grasp and anticipate. Because both most drivers and the auto industry value the risk of possible uncontrollable dangers, the inhibition threshold is the highest to be transported as a passenger in this way.

In a tragic accident in Florida, a Tesla driver who drove with the autopilot on had a fatal accident. All the assurances that this tragic accident was an exception through a chain of unfortunate circumstances did not help much. The driver has died, and the Tesla manufacturer is held liable [17]. Other examples where intelligent autonomous moving or flying systems are used are the military drones. These systems can replace flight pilots and locate and destroy distant targets. Even more worrying is the industrial development in countries such as China, where democracy is lacking. As the world's second most powerful economy and a major vehicle and developer of technologies of the future, such as Artificial Intelligence, the state controls the Internet and uses this technology to control its citizens. In China, for example, the social network platform Facebook, the short message service Twitter, the video platform YouTube or Google's search engine are blocked for the citizens.

According to Reuters, Wang Huning, a member of the powerful Standing Committee of the Communist Party during the World Internet Conference 2017 in the city of Wuzhen, said, "China is ready to develop new rules and systems of Internet administration that will affect all parties serve and counter present imbalances ". At the same conference, the goal of the Chinese government was to make China "the leading nation in the world by 2030 when it comes to artificial intelligence and its widest possible use." This would mean that states like the USA would have to make more effort to develop these future technologies if they wanted to continue to be world leaders [1].

Another important question is training, further education and the associated staff capacity requirements, which can fluctuate greatly over time [8]. While in China, the state is pushing internet technologies and artificial intelligence [1], Western countries are facing problems in terms of providing enough skilled labour.

\section{Conclusions}

The article has broadly demonstrated that the implementation of Industry 4.0 goals is possible, thanks to increasing automation and artificial intelligence. These technologies generate enormous amounts of data that can be intelligently processed. However, it was also shown that there were hardly any legal regulations for the acquisition and processing of many data. It is not clear at all whether the generated data can be stored and processed properly. Also, it is not clear who are the owners of the data if this data is generated without the consent of the actual data providers.

The article also shows that many data, such as the raw material of the future, has a very high value, which has become a rapid economic factor. In this context, it also needs to be clarified how the income from this sector of the economy can be distributed. In the automation sector, millions of jobs are lost in the manufacturing industry, where Industry 4.0 is being implemented, while the owners of these industries optimize their profits. Those who lose their jobs, however, remain unintentionally suppliers of data that can be used economically. Is this condition acceptable or does it have to be discussed in terms of socio-political policy? 
Another question is how far can full automation go? There, where automation facilitates the work, nothing would be wrong. But if massive job losses are lost through automation, will these jobs be replaced by new ones? Will autonomous systems decide life and death?

Due to globalization, it is no longer clear where the legal boundaries are drawn. Are national rights repealed? Or are normal people exposed to the arbitrariness of large corporations? Are then the interests of the corporations put over the interests of the individual states?

In summary, it can be said that the technical goals of Industry 4.0 can be realized in connection with artificial intelligence and the processing of large amounts of data. However, socio-political aspects are neither solved nor duly addressed those problems.

\section{References}

[1] Armbruster A.," Ich sorge mich um Menschen, die denken wie Maschinen," FAZ.NET, 2017.

[2] "BMW US Manufacturing Company, " Spartanburg County, South Carolina, 2013.

[3] Bundesministerium für Wirtschaft und Energie, "Referat Öffentlichkeitsarbeit: Gemeinsame Plattform Industrie 4.0 startet, " 2015.

[4] Hermann M., Pentek T., Otto B. (2016). "Design Principles for Industrie 4.0 Scenarios," 49th Hawaii International Conference on System Sciences (HICSS), ISSN 3928-3937, 2016

[5] Hirsch-Kreinsen H., "Einleitung: Digitalisierung industrieller Arbeit." Hartmut Hirsch-Kreinsen/Peter Ittermann/Jonathan Niehaus (Hrsg.): Digitalisierung industrieller Arbeit. Die Vision Industrie 4.0 und ihre sozialen Herausforderungen, Baden-Baden, 2015.

[6] Kagermann H., Lukas W.-D., Wahlster W.: "Industrie 4.0: Mit dem Internet der Dinge auf dem Weg zur 4. industriellen Revolution." VDI-Nachrichten, April 2011.

[7] Merkel A. "Daten sind die Rohstoffe des 21.Jahrhunderts," FAZ.NET. 2016

[8] Spath (Hrsg.) D., Ganschar O., Gerlach S., Hämmerle M., Krause T., Schlund S., "Fr aunhofer Institut für Arbeitswirtschaft und Organisation IAO," Produktionsarbeit der Zukunft - Industrie 4.0, ISBN: 978-3-8396-0570-7, 2013

[9] Vladareanu, L., Curaj, A., Munteanu, R.I., "Complex Walking Robot Kinematics Analysis and Plc Multi-Tasking Control", Rev. Roum. Sci. Techn. - Électrotechn. et Énerg., 57 (1), pp. 90-99, 2012.

[10] Vladareanu, V., Dumitrache, I., Vladareanu, L., Sacala, I.S., Tont, G., Moisescu, M.A., "Versatile Intelligent Portable Robot Control Platform Based on Cyber Physical Systems Principles," Studies in Informatics and Control, Vol. 24, Issue 4, pp. 409-418, 2015.

[11] Vladareanu, V., Munteanu, R.I., Mumtaz, A., Smarandache, F., Vladareanu, L., (2015). "The optimization of intelligent control interfaces using Versatile Intelligent Portable Robot Platform," International Conference on Communications, Management and Information Technology (ICCMIT'2015), Procedia Computer Science, 65, 225-232

[12] $\quad * * *-$ https://www.krollontrack.de/blog/wer-ist-der-eigentuemer-der-daten/6712, 2017.

[13] $\quad * * *$ - Watson solutions and APIs, https://www.ibm.com/watson/de-de/loesungen/, 2017.

[14] $\quad * * *-$ https://de.wikipedia.org/wiki/Webcrawler, 2017.

[15] $\quad * * * \quad-\quad$ https://www.heise.de/newsticker/meldung/Amazon-Roboter-sollen-auch-inDeutschland-Ware-zum-Mitarbeiter-bringen-3706026.html, 2017.

[16] $\quad * * *-\mathrm{http}: / / \mathrm{www}$.airliners.de/kann-flugzeug-antworten-cockpit-15/37085, 2017.

[17] $\quad * * *-$ http: //www.sueddeutsche.de/auto/selbsfaren ... - The Tesla Statement, 2017. 